\title{
Perspectiva Constitucional dos Meios Privados de Resolução de Conflitos
}

\author{
Constitutional Perspective on the Private Dispute Resolution Methods
}

\author{
Clarindo Epaminondas de Sá Neto ${ }^{1}$ \\ George Lucas Souza Diógenes ${ }^{2}$ \\ José Albenes Bezerra Júnior ${ }^{2}$ \\ ${ }^{1}$ Universidade Federal de Santa Catarina, Florianópolis, SC, Brasil \\ ${ }^{2}$ Universidade Federal Rural do Semiárido, Mossoró, RN, Brasil
}

Resumo: O objetivo deste artigo é delimitar a posição que os métodos privados de resolução de conflito ocupam no ordenamento constitucional brasileiro. Mais especificamente, o que se busca é aferir se esses métodos podem ser abrigados sob o sistema protetivo das cláusulas pétreas, considerando que os seus usos se relacionam com o acesso à justiça interpretado no inciso $\mathrm{XXXV}$, artigo $5^{\circ}$ da Constituição de 1998, o qual, na qualidade de garantia individual fundamental, é resguardado pelo artigo 60, parágrafo $4^{\circ}$, inciso IV. Assim, o caminho percorrido aqui será identificar se e em que medida o uso dos métodos privados de resolução de conflitos se insere no núcleo daquela garantia. Tal relação será exposta com recurso à análise filosófica do tema sob a perspectiva do Contratualismo e a temas da teoria geral do direito relativos ao poder soberano e à jurisdição, por meio do método hipotético-dedutivo e de revisão de literatura e análise documental.

Palavras-chave: Acesso à Justiça. Cláusula Pétrea. Contratualismo. Direito Constitucional. Resolução Privada de Conflitos.

\begin{abstract}
The objective of this article consists in the delimitation of the place occupied by the private dispute resolution methods within the frame of the Brazilian constitutional order. More specifically, the main goal is to determinate if those methods can fall under the protective system of the eternal clauses, considering that their practices are associated with the access to justice, which, as a legal guarantee, is declared by the fifth article, XXXV, of the current Brazilian Constitution. The same Constitution, according to the $60^{\text {th }}$ article, IV, protects that guarantee as an eternal clause. Thus, we investigate if and to what extent the use of private dispute resolution methods can be found inserted in the core of the legal guarantee of access to justice. Such relation will be mainly explained with the help of the philosophical themes provided by the Contractualism and also by legal theory themes concerning sovereign power and jurisdiction. In order to achieve this goal, this article employs the hypothetical-deductive method assisted by literature review and documental analysis.
\end{abstract}

Keywords: Access to Justice. Constitutional Law. Contractualism. Eternity Clause. Private Resolution of Conflicts.

Recebido em: 30/10/2020

Revisado em: 23/11/2020

Aprovado em: 30/11/2020 


\section{Introdução}

As dificuldades que percorrem corredores e salas dos tribunais e dos fóruns do País coroam o amontoado de adversidades experimentadas pelo povo brasileiro. Os conflitos, potencializados na sortida facetagem das relações humanas recepcionáveis pelo direito, apresentam-se submissos em colunas de papéis que tentam sustentar um edifício pesado ou como desembrulhados de códigos binários em telas vítreas nas quais transparece a reprodução de cópias.

No entorno, debates constitucionais, administrativos e processuais avançam sugestões com o propósito de sanar a morosidade e a baixa qualidade que acometem a prestação jurisdicional e que pervertem ou, no mínimo, fazem desacreditar o significado do acesso à justiça.

Alguns dos resultados dessas discussões tomam corpo recentemente com as modificações legislativas e as orientações e as diretrizes de órgãos autorizados quanto à administração de controvérsias entre os particulares e mesmo entre estes e o Poder Público no contexto da crise numérica de processos. Esses eventos fazem brotar novas perspectivas acerca do acesso à justiça com base nos meios privados de solução de conflitos, de modo que aquilo que então era subestimado e até constituía razão a suscitar inconstitucionalidade é agora posto sob os auspícios de muitos que neles acreditam ver emprego adequado para dar efetividade ao projeto constitucional.

Se, no entanto, esses meios ampliam sua esfera de aplicabilidade, é incerto inicialmente se a sua eficácia está a depender do arranjo conjuntural a que se fez menção logo nas primeiras linhas e se sua promoção é mero fruto dos reveses do Judiciário e da conseguinte adoção de uma nova política. Como também é incerto se, por mais que sejam colhidos resultados positivos com os novos rumos, esse progresso tardio virá a encontrar eventual retrocesso em sua jornada.

É por isso e em vista da evidência expressa nas incontáveis possibilidades de mutação no ordenamento jurídico que nos pomos face ao problema de investigar se os meios privados de resolução de conflitos gozam de alguma proteção no ordenamento jurídico brasileiro face à atividade legiferante. 
Para satisfazer a pergunta, é utilizado o método hipotético-dedutivo com auxílio de pesquisa bibliográfica e material documental, abordando desde a contemplação filosófica sobre os fundamentos desses meios nos quadros do próprio desenvolvimento humano em sociedade até os estudos sobre o núcleo do direito de acesso à justiça no ordenamento pátrio.

A importância de tentar responder a essa questão está na contribuição ao esclarecimento das atitudes e dos modelos que insistem no tratamento insuficiente dos conflitos; na afirmação da independência dos meios privados de resolução de conflitos do contexto de fracasso das instituições jurídicas e políticas, ao mesmo tempo em que examina o efeito positivo sobre estas; e, principalmente, na compatibilização entre o modelo de poder e a maior autonomia aos jurisdicionados.

\section{A Sociabilidade Humana e os Fundamentos do Poder Soberano}

De princípio, quando se considera o tema que orienta este trabalho, salta um problema que, inicialmente, parece pertencer à mera ordem de nomenclatura e estilística. Quando muito, aparenta apenas estar associado à ênfase atribuída por um ou outro autor a fim de acrescer a importância do seu objeto de estudo. Fala-se, com isso, da questão de designar os meios privados de resolução de conflitos de "alternativos" ou "originários".

Isso justifica parcialmente a razão de se adotar aqui o termo "privado" em vez de aderir àquelas outras terminologias. Também não se poderia substitui-las pelo emprego da sua nomeação como "consensuais", uma vez que, dentro da classificação correntemente aplicada, vias de alto relevo restariam excluídas com tal opção, como é o caso da arbitragem. As demais explicações referentes à nomenclatura enunciada no título desta inquirição e ao longo de suas páginas serão oferecidas em outros momentos.

Contudo, o que é necessário ter sob atenção é que o que figurava então como questão de órbita significativamente estreita oculta uma discussão de abrangência superior. A razão para essa afirmação reside no fato de que optar pela alternatividade ou pela originariedade do objeto pressupõe obrigatoriamente os debates da resolução de conflitos dentro da perspectiva de formação e desenvolvimento do governo (e a instauração 
do Poder Judicial) e o que possam ser estágios prévios a esse ponto. Em outros termos, pressupõe uma gradação relativa a estágios de desenvolvimento e aplicação de formas de resolução de conflitos. Logo, aí também está incluído o estudo de como essas formas não apenas coexistem e se relacionam, mas como sucedem uma à outra.

Não menos importante, a decantação dos fenômenos abrigados por aquele uso linguístico oferece também a vantagem de se abster tanto quanto possível de sobrepor uma categoria sobre outra. Tal atitude, além de demasiadamente tragada em subjetivismo, anteciparia, de forma obscura e insatisfatória, conclusões que seriam definitivamente mais úteis se desenvolvidas acuradamente e legadas a momento posterior.

Portanto, a análise que se abre nesta altura tenderá a clarificar não exclusivamente um padrão sequencial, porém, principalmente, a possibilidade de relações que existem entre a esfera estatal e a privada no que concerne à pacificação social. E, uma vez reveladas, a essas interações sobrará a depreensão dos princípios que as coordenam e, só então, as consequências pertinentes.

Para tornar exequível, nesses moldes, o projeto, é preciso externar uma posição de seletividade quanto ao material que trata da discussão mais ampla apontada acima. Tal restrição informa-se por meio das opções teóricas feitas por vários autores ao ocupar-se dos meios não estatais de solução de conflitos, pelo que logo se discerne a adesão a premissas e corolários remetentes às teorias contratualistas, como é perceptível, ilustrativamente, na obra de Bacellar (2012).

Entre as primeiras correntes que se põem a explicar o surgimento da sociedade civil e a comunhão de homens sob uma autoridade comum, se pode destacar o contratualismo. Faz-se observar junto com Voegelin (1998) que, não obstante o ímpeto que o contratualismo logrou nos séculos XVI ao século XVIII com a publicação de suas obras mais representativas, a analogia do surgimento do governo com a conclusão de um contrato existe, pelo menos, desde o período helênico, a notar pelas menções às quais Platão (2014) reservou espaço em A República. Mais especificamente, é de se referir ao seu livro II, no qual é reproduzido diálogo por ocasião do qual Sócrates sustenta que a justiça é um bem desejável por si 
mesmo e por aquilo que dela decorre. Assim, rejeita que sua origem possa estar encerrada no contrato social e que seja seguida apenas se estando apoiada sobre uma atitude coercitiva.

Isso é suficiente para verificar a abrangência do campo teórico almejado e, precisamente por razão de tal investigação ter se ramificado grandemente em seu conteúdo, urge aqui selecionar e concentrar-se sobre os pontos mais relevantes em virtude da frequência com que são trazidos ao debate. Dessa forma, ocuparão aqui espaço, especificamente, as tratativas da filosofia política de Thomas Hobbes, John Locke e Jean-Jacques Rousseau.

Outro significante motivo para realizar um corte orientado na breve análise de pontos centrais da produção intelectual dos autores mencionados e não de outros é que a aceitação ainda que parcial de suas teses encontra-se explícita ou implicitamente imiscuída com a formação dos Estados modernos e das políticas jurídicas por eles eleitas. Além disso, a incorporação consciente ou não de perspectiva tão antiga como o é a contratualista permite-se sentir também na doutrina de juristas brasileiros que se ocupam do estudo e da promoção dos meios privados de solução de conflitos, de forma que é uma pertinente exigência conceder algum tempo para o exame dos pilares sobre os quais se sustentam, para que, dentro de seu próprio discurso, não remanesçam abrigadas ideias contraditórias que terminam por redundar no entrave ao pleno desenvolvimento do alargamento e da releitura da concepção de acesso à justiça.

A grosso modo, pode ser preliminarmente definida como campo comum das teorias contratualistas a ideia de um consentimento não necessariamente explícito que alberga uma restrição de determinada parcela de liberdade de ação em razão da instituição de um poder apto a regular as condutas.

Tem-se, num primeiro instante, que um dos principais desenvolvimentos que o contratualismo percebeu encontra-se no pensamento de Hobbes (2014), cuja base firma-se na cisão do estado pré-político, que adquire então a denominação de estado da natureza, e do momento em que é posto o governo, o qual, uma vez constituído e emanado na pessoa 
do soberano, é titular da obediência dos súditos a despeito de qual venha a ser o conteúdo das ordens expedidas.

Opera-se, assim, um corte entre qualquer justificação ética ou moral do ordenamento jurídico, para adotar a linguagem de Kelsen (2009), e o direito posto pelo soberano. Ou ainda, a desvinculação entre a ordem posta e o direito natural.

Soma-se a isso outro elemento característico de sua filosofia política, qual seja, a exposição do indivíduo à profunda semelhança de um espécime selvagem. A situação primeva dos seres humanos é, no pensamento de Hobbes (2014), o estado de guerra, entendido como inclinação guiada pela visão egoísta acerca das motivações e da sociabilidade dos homens, que, em evidência da equivalência relativa de forças, são impelidos inflexivelmente ao pacto social e sua subsequente obediência.

Todavia, para o tema abordado, esse não é o único efeito que a filosofia hobbesiana desdobra. É que a oposição diametral a que são colocados os dois estágios das relações sociais deságua na interpretação linear de evolução da justiça, circunscrevendo-a tão somente ao aparato e aos decretos estatais. Incide numa gradual expansão das vias estatais em detrimento da justiça privada. Em um olhar mais próximo, é judicioso mesmo dizer que, nesse momento, a expressão "justiça privada" transmuta-se em oxímoro, uma vez que o autor reduz a justiça à lei.

Nesse contexto, ainda que fosse concebível que normas fossem editadas disciplinando os meios privados de solução de conflitos, isto é, tivessem estes forma e procedimento previamente definidos, sua aplicação concreta seria resumida à mera representação da atividade judicial.

A crítica que aqui é oposta a Hobbes encontra apoio em produção de Spengler (2010), por ocasião de que se assere como produtos desse modelo o enfraquecimento da faculdade de administração consensual e privada dos conflitos e a promoção da condição passiva dos indivíduos, dado o estado destes tal como reféns em relação à necessidade de resguardar-se contra a instituição de qualquer forma de "pacificação" pela vingança e pela deliberação autônoma nos termos propostos pelo filósofo. 
A seu turno, Locke (1998) apresenta várias semelhanças com a teoria hobbesiana, o que se justifica por ambos autores partirem de hipóteses comuns, como é o caso da suposição do estado da natureza, ainda que com suas disparidades, e por compartilharem da inclusão numa mesma escola da filosofia política.

Contudo, as divergências da teoria lockeana sobre o assunto alcançam sensível expressão na perspectiva que o autor toma ao tratar da condição natural dos homens, de modo que tece consequências irreconciliáveis com as de seu conterrâneo. Nomeadamente, o que arca com a responsabilidade dessa separação é o foco que Locke (1998) empresta à falta de garantia e segurança que o indivíduo percebe previamente à instituição da soberania em lugar de imprimir uma descrição das origens da sociabilidade humana subsidiada pela inerência ao homem de atributos extensivamente denegrintes.

O efeito conferido por essa mudança fundamental de perspectiva é que o homem daquela situação primitiva não mais é caracterizado como essencialmente imoral ou amoral, mas retém, em alguma medida, os padrões de moralidade e justiça a aplicar referente às condutas suas e de outrem, porém de forma que servirá como juiz de sua própria causa e também lhe caberá executar seu julgamento. Equivale a acentuar que a soberania e a justiça não surgem ao mesmo instante nem esta fica confinada àquela e nem a seus regulamentos pode ser equalizada, muito embora a lei assuma importância central na obra examinada como garantia contra investidas de um poder que eventualmente se pretenda tirânico. Dessarte, Locke (1988) reconhece limites à atuação do soberano, essencialmente no que diz respeito à proteção da vida, da propriedade e da liberdade.

Outra forma de tratar a discussão está na análise a partir da leitura e do emprego da terminologia que Steele (1993) oferece-nos: a despeito da linguagem confusa de que Hobbes se utiliza na sua teoria do contrato social, esta é intentada a reproduzir-se sobre o conceito de alienação, de forma que os direitos envolvidos no pacto entre os indivíduos são cedidos em razão de um soberano, não sendo admitido que tais direitos regressem aos seus titulares originários exceto em caso de ocorrer, por fatores externos, a dissolução daquele poder constituído. Locke, embora descreva 
a ocasião pela qual os homens abrem mão de ser juiz e executor de sua própria causa, o faz em termos de autorização, por meio da qual é aceitável e legítimo, do ponto de vista interno, uma dissolução do governo estabelecido se este não se atenta às definições mínimas cunhadas naquela autorização.

Contudo, apesar de que as consequências extraídas dos conceitos lockeanos apontem para uma mais larga concessão à autonomia privada, persiste ainda a dificuldade, em virtude da ênfase posta sobre o Estado, de extrair de sua teoria qualquer fundamentação mais precisa do direito ao uso dos meios privados de resolução de conflitos sem imputar-lhe mais do que realmente sustentou em suas teses.

A esse respeito, se faz salientar ainda a seguinte observação:

A lei é não-excluível porque todos gozam dos seus frutos simplesmente por viver em sociedade [...] A teoria dos bens públicos prediz que entidades privadas não podem prover leis e, a menos que o governo as proveja, a sociedade não consegue prosperar. Teóricos do contrato social, de Hobbes e Locke a Buchanan e Tullock, sustentam essa visão. (CAPLAN; STRINGHAM, 2008, p. 2, tradução nossa)

Por fim, também na obra de Rousseau (1996) se encontram mais entraves do pensamento contratualista ao uso e ao desenvolvimento dos meios privados de solução de conflitos. Porém, isso sucede-se em teses muito diversas daquelas que formavam o cerne das duas outras obras predecessoras.

É que, admitindo que os homens gozavam de liberdade no estado da natureza, Rousseau objetiva, no capítulo VI do livro I de sua obra $O$ Contrato Social, estabelecer o modo em virtude do qual os indivíduos, ao se associarem, retenham-se no gozo do mesmo tanto de liberdade quanto antes.

Nota-se, preliminarmente, quão é obscuro entender por qual razão as pessoas que, tendo desfrutado de uma liberdade originária, reúnem-se por meio do contrato social para tornar a ser tão livre quanto antes. A esse 
respeito, Pavlovic (1997) desfaz o embaraço ao esclarecer que a liberdade natural é guiada tão somente pelos apetites humanos, ao passo que, posteriormente sob a sociedade civil, transmuta-se precisamente numa liberdade revestida de moralidade.

A primeira grande dissemelhança consiste quando da destinação dada aos direitos transferidos pelos homens no ponto de transição entre os estados pré-político e político: o próprio povo é depositário e destinatário desses direitos, tratando-se de uma soberania popular e ilimitada.

O núcleo da soberania popular reside no que Rousseau designou de vontade geral, que difere da vontade de todos por se referir:

[...] somente ao interesse comum, enquanto a outra diz respeito ao interesse privado, nada mais sendo que uma soma das vontades particulares. Quando, porém, se retiram dessas mesmas vontades os mais e os menos que se destroem mutualmente, resta, como soma das diferenças, a vontade geral. (ROUSSEAU, 1996, p. 37)

O podamento das disparidades (os mais e os menos) e sua subalterância são uma forma quase simbólica e bastante eficiente de descarte e deformação daquele rico campo de conflitos representado pela vontade de todos ao forçá-lo nos moldes mais estreitos da vontade geral.

Encontra relevo também na sua obra a descrição orgânica do Estado. Isto é, a união dos indivíduos transforma-se, imbuída do espírito de uma soberania indivisível, em uma única entidade, a semelhança de um organismo, donde a ofensa cometida a qualquer de suas partes representa uma ofensa ao todo.

Nesse sentido, os interesses privados quedam-se dissolvidos dentro da vontade geral e, apenas conformando-se a esta, os indivíduos (que agora constituem o povo) logram a liberdade.

Saindo por outro ângulo, é dizer que um dos traços característicos da teoria ora analisada é a "[...] idéia de que todos os direitos, inclusive os de propriedade, são direitos dentro da comunidade e não contra a comunidade" (SABINE, 1973, p. 536 apud PAVLOVIC, 1997, p. 22, tradução nossa). Isso porque a estrutura do pensamento rousseauniano está foca- 
lizada na promoção do coletivismo como fator de legitimação e mesmo essência dos diferentes aspectos da ordem política.

Pode-se evidenciar que a aplicação de artifícios direcionados à pacificação de disputas para além da autoridade e das repartições públicas e a gradual conformação à vontade geral percorrem vias opostas. Os primeiros, por mais que admitam frequentemente ter condicionados sua validade e seu funcionamento, demandam certa autonomia em relação à legislação para produzir alguma eficácia.

A subordinação do exercício legítimo da soberania à vontade geral naqueles termos é, pois, contraditória ao emprego de dispositivos que possam situar-se fora dos quadros legais votados pelo povo. Em última análise, tal prática poderia compreender-se como atentatória ao interesse nacional. Ademais, certa desregulamentação é o requisito mesmo para a caracterização dos meios privados como tais, providenciando que não se transfigurem numa tentativa de replicação das vias estatais existentes.

Viu-se, até então, que esta pesquisa ocupou-se da avaliação dos tópicos conflitivos das teorias contratualistas no que concerne à busca de princípios para a sustentação das vias privadas de solução de conflitos. Os resultados são, em grande medida, desencorajadores quando é contemplado precisamente o efeito contrário: quer aquele advindo da depreciação dos indivíduos, quer como inferência de uma noção positiva de liberdade associada ao conceito de vontade geral. Ou ainda a palidez do proveito esperado da teoria lockeana que, não obstante perfaça alicerce à autonomia privada e à limitação do governo, persevera na lei estatal para dirimir disputas.

Nada obstante, o desdobramento da análise até o presente estágio não se resume no oferecimento de conclusões negativas no sentido de evidenciar perfis incompatíveis, insuficientes e mesmo opostos ao fundamento independente que se busca para a existência e aplicação das formas privadas de gerenciamento dos interesses conflitantes.

O que se tornou passível de ilação foi que uma leitura linear e progressista residente na explicação da dinâmica expressa no binômio soberania-justiça não só coincide como é causa da intumescência estatal e da invariável submissão dos conflitos ao poder central. Mas uma consequên- 
cia daí advinda é-nos particularmente cara: a apresentação dos postulados contratualistas como raízes que se projetam diretamente no conjunto de fenômenos distintos a que coube, por vários autores, o título imperfeito e obscuro (uma vez que, despreocupadamente, congrega sob uma mesma categoria manifestações verificáveis por critérios muito díspares) de cultura demandista.

Quanto à pendência - nomeadamente, a de identificar uma base comum e independente ao objeto da pesquisa - carece examinar contraponto teórico a fazer oposição à promoção da convergência da origem da justiça com a lei ou na vinculação destas a uma soberania ilimitada que encontra sua legitimação numa tendência coletivista.

Nesse ínterim, é de salientar-se o magistério de Hutcheson (2006) que, tornando à filosofia clássica, retoma a inserir a justiça entre os bens desejáveis por si só. De mais a mais, também lhe ocorre de que o ser humano deseja a companhia de seu semelhante por ser tal presença agradável por si, embora também possa ser motivada por várias circunstâncias. Desse modo, a sociabilidade humana passa a ser enfatizada como algo inerente e natural ao indivíduo, de modo que não subjaz fundamento em tencionar entre si os estados de desenvolvimento das relações sociais.

As associações entre homens são, outrossim, produto da razão e, sendo esta integrante da constituição natural do ser humano, não subsiste motivo para entendê-las como antinaturais, concluindo, junto a Aristóteles, que os homens são criaturas adequadas por natureza à política. Daí a crítica de Hutcheson (2006) à impropriedade da denominação "estado da natureza" e, por conseguinte, sua preferência por adotar a nomenclatura "estado de liberdade do governo" (state of liberty from human government).

Hutcheson (2007) também não hesita em reconhecer a presença de sentimentos egoístas e a sujeição que, de forma contumaz, os indivíduos desenvolvem frente às inclinações nocivas. Entretanto, ressalta que não são o substrato da formação do governo civil apenas o receio e o precaver contra os possíveis danos por ocasião da ausência de um autoridade legítima.

O que fortemente nos aconselha a congregar-nos sob um poder comum, explica o professor escocês, é nossa faculdade concernente à apre- 
ciação das qualidades superiores de que alguns de nossos semelhantes dispõem, de sorte que, por suas virtudes e habilidades, é razoável reservar-lhes posição de comando e direção na vida social. Rejeita, então, uma explicação pautada no utilitarismo egoísta.

Aliás, sendo aquela apreciação uma tendência incluída na constituição humana, não é razoável assumir sua supressão quando da instituição de um governo civil. Ao contrário, é perceptível que essa inclinação permanece a manifestar-se não só na base da vida política e nos seus atos constitutivos mais essenciais, a exemplo das eleições. Identicamente, nos aspectos mais íntimos da experiência privada, as relações são, não raro, qualificadas pela disposição em valorizar os aspetos positivos de um indivíduo de tal modo a não apenas lhe prestar uma atitude reverente, mas ainda a submissão de experiências sociais e íntimas.

Essa tendência natural tem afinidade direta com um dos princípios da arbitragem, nomeadamente o princípio da especialidade, conforme explica Scavone Júnior (2014), na medida em que as habilidades específicas constituem motivos para a eleição de um ou outro árbitro. Mas, se tomado o princípio da especialidade num sentido mais amplo, isto é, além dos limites e das divisões do conhecimento formal a que são restritos, é possível fazê-lo abranger também outros métodos privados de solução de conflitos que envolvam a presença de um terceiro originariamente estranho à relação.

Observe-se, afinal, que nessa compreensão não se incluem apenas governantes e magistrados, senão também, exemplificativamente, árbitros, mediadores e conciliadores.

Nessa nova perspectiva, que recusa a identificação da origem da justiça com a fundação das instâncias políticas, restam conciliados tanto o desejo por segurança nas relações sociais, quanto sua tendência natural para apreciar e buscar aplicar valores e virtudes da pessoa humana, porquanto a sociabilidade apresentada naqueles parâmetros não germina unicamente por força de circunstâncias negativas, senão ganha uma condição positiva na consideração do outro e de seus atributos. 
Perspectiva que não se encerra na investigação do pensamento de Hutcheson, mas encontra razoável eco mesmo em obra representativa da filosofia jurídica analítica, conforme colhe-se nessa medida:

Pode-se imaginar uma sociedade em que existam determinadas regras que prescrevem uma conduta e sejam sustentadas por sanções coercitivas, mas na qual não existam órgãos primários aplicadores da lei. A decisão de que uma lei foi violada e a aplicação de sanções pode ser confiada à parte prejudicada ou à sua família, ou a qualquer membro da sociedade, contanto que o violador não tenha sido punido por outra pessoa etc. Os órgãos primários surgem no momento em que o poder de decidir sobre a aplicação de tais sanções está concentrado nas mãos de um número relativamente pequeno de pessoas, que são indicadas ou cuja tarefa lhes é confiada primeiramente por causa de suas supostas capacidades, ou porque a merece, e não por causa de suas relações coma parte prejudicada ou com o violador da lei, contanto que tais pessoas exerçam seus poderes por um período relativamente longo e possam usá-los em um número indefinido de casos. (RAZ, 2012, p. 258-259, grifos nossos)

O que se quer expor com isso é a presença de um princípio de estruturação da sociedade a cobrir a fundação não estatal das relações sociais e a reger os meios privados de solução de conflitos, os quais encontram, nesse ponto, os alicerces de sua existência e significância.

De mais a mais, a sua revelação tomada como fruto de elemento constitutivo da natureza humana - a sociabilidade, que Reale (1999, p. 214) explicita como "condição de possibilidade' da vida de relação" enreda-se na dignidade da pessoa humana, não somente na proporção em que se acha como característica comum a todos indivíduos, senão também lhes diferencia como espécie e aperfeiçoa a consciência de si e do outro.

Essa amplitude aponta suficientemente para enjeitar a rasa apologia que se espreme na sustentação da importância daquelas vias apenas com respaldo em sua antecedência em relação às estatais, como fosse a anterioridade de uma manifestação critério autoevidente e suficiente de com- 
provação de relevância social, pelo que falar em evolução sempre constituiria um contrassenso.

Esse princípio aprofunda-se mais no objeto de estudo tanto quanto deixa revelar que a estrutura judiciária e os métodos como arbitragem, conciliação e mediação encontram na sociabilidade humana um fator comum e ao mesmo tempo diferenciador que ordena ambos em uma espécie de dinâmica em que não subjaz contraposição, senão mútua dependência para lograr seus fins particulares e comuns. Por essas razões, isso ainda implica na transcendência e no abandono de qualquer postura ad hoc em relação à aplicação das soluções paraestatais motivada pela crise do Judiciário.

Enfim, é desvelada a circunstância em que a soberania nasce pelo contrato social de maneira não excludente a respeito das outras vias de pacificação. Assim, a ordem jurídica estatal desenvolve-se de lado a lado com os equivalentes privados, de modo que a primeira garante que os últimos não se degenerem numa justiça privada que antes constituiria ameaça aos fundamentos da vida social. No caminho inverso, aqueles meios conferem autonomia aos indivíduos na administração de suas contendas com auxílio de técnicas mais variadas e específicas, percebendo maior estabilidade social que se reflete no reforço legítimo da soberania instituída em proporção à crescente posição ativa das pessoas no universo conflitante em que se encontram, pondo de parte as inspirações totalitárias que deságua numa interpretação inflada do poder soberano.

\section{Alcance da Ordem Jurídica e Solução dos Conflitos de Interesses}

Dado que se tratou, no primeiro tópico, de localizar e dissolver incompatibilidades entre os fundamentos de uma política mais abrangente de resolução de conflitos e o conceito explícita ou implicitamente incorporado de soberania, se faz descer este estudo à problemática distinta como mais pertinente (considerada sua inserção no âmbito da análise jurídica) manifestação daquele conceito: a jurisdição. 
Esse elemento tece o elo mais expressivo entre a análise antecedente - que, por envolver conceitos como sociabilidade, soberania e poder, cobra maior vinculação à ciência política e à jusfilosofia - e a perscrutação da possibilidade de encaixar o objeto de pesquisa como direito albergado pelos dispositivos constitucionais brasileiros. Isso se dá em evidência do fato de essa última etapa abrir-se precipuamente para questões de um ordenamento positivo em particular.

Não é indagado, nesse sentido, a extensão da jurisdição com vistas ao seu exercício sobre um determinado território, nem ao seu desdobramento no fenômeno temporal. Lida-se antes com o alcance da recepção das condutas humanas na ordem jurídica e, mais especificamente, é ponto de partida a tese apoiada por Kelsen (2009) de que o direito rege todas as condutas humanas possíveis, quer de forma positiva, quer negativamente. Isto é, o sistema jurídico dota-se de totalidade suficiente para que toda ocorrência seja-lhe remetida sob o binômio permitido-proibido.

Não significa isso que toda a potencialidade da ação humana encontra-se previamente descrita nas leis estatais. Nessa altura, não é dispensável salientar que a completude do sistema não coincide com a infalibilidade relativa ao tratamento das possíveis controvérsias entre interesses dentro de uma mesma ordem.

Essa situação é esclarecida nas seguintes linhas:

A liberdade de uma pessoa que assenta no fato de uma determinada conduta lhe ser permitida, por não ser proibida, é garantida pela ordem jurídica apenas na medida em que esta prescreve às outras pessoas o respeito desta liberdade e lhes próbe a ingerência nesta esfera de liberdade [...] Nem toda conduta permitida - no sentido negativo de não-ser-proibida - é garantida pela proibição da conduta de outrem que impeça aquela ou se lhe oponha; nem a toda conduta de uma pessoa por este motivo permitida corresponde uma obrigação correlativa de outra pessoa. Uma determinada conduta de um indivíduo pode não ser proibida pela ordem jurídica e ser, neste sentido, permitida, sem que seja interdita pela mesma ordem jurídica a conduta de um outro indivíduo que àquela se opõe, por forma a também esta última conduta ser permitida. [...] Se não é proibi- 
da (e, nesse sentido, é permitida) a conduta de um indivíduo que é contrária à conduta de um outro indivíduo também não proibida (e, neste sentido, permitida), é possível um conflito face ao qual a ordem jurídica não toma qualquer disposição. [...] A ordem jurídica não pode, de forma alguma, procurar impedir todos os conflitos possíveis. (KELSEN, 2009, p. 46-47)

Preste-se agora atenção que a perspectiva do autor não está a dizer com a impossibilidade da ordem jurídica em impedir todos os conflitos que existam lacunas no direito, no sentido que é comumente atribuível ao termo.

A afirmação é de ser antes entendida no que diz respeito à inexequibilidade em erigir representações normativas a incitar um padrão de conduta em toda possível conjuntura. Isto porque a órbita dos conflitos é necessariamente mais ampla que a prestação jurisdicional do Estado, mesmo que a ela possa estar inteiramente subordinada. Quanto maior a desproporção entre esses pontos, maior a tensão na sociedade, a qual pode ser resolvida hipotética e mormente de duas formas: 1) aumento e pormenorização incessante da regulação estatal; 2) concessão de vias e métodos significativamente desvinculados da esfera pública.

A primeira alternativa produz um efeito cíclico e de corrosão no fortalecimento das instituições jurídicas quando se recorda da lição de Hart (2009) acerca da textura aberta do direito em razão de sua generalidade e do seu recurso linguístico, em vista de que a decisão do juiz confere o sentido definitivo e autorizado da norma. É que insaciável produção legislativa multiplica os espaços de divergência hermenêutica e o poder autorizado na aplicação das regras de direito.

Essas observações não forçam o pensamento de Hart a aceitar as teses que explicam o quadro nos moldes de um "governo dos juízes" ou mesmo num ceticismo em relação às normas. Mas ocorre que todos esses problemas suscitados quando da contemplação da resolução de conflitos dentro do direito estatal movem o seguinte dilema:

Se a concepção ético-política do juiz toma o lugar da concepção ético-política do legislador, este abdica em favor daquele. A tenta- 
tiva de limitar esta atribuição de competência aos casos que o legislador não previu tem, no entanto, de esbarrar com o fato de o legislador também não poder determinar esses casos. Se os pudesse determinar, regulá-los-ia ele mesmo positivamente. (KELSEN, 2009, p. 275-276)

Essas teses se opõem, portanto, à necessidade de apresentar uma resposta aceitável e coesa aos conflitos de interesse dispersos por todo corpo social e, ao mesmo tempo, preservar a harmonia entre os Poderes que se estruturam dentro da realidade sociopolítica da nação. Todavia, por mais que os "espaços preenchíveis" da norma e o ativismo judicial (tema que será discorrido em momento posterior) partilhem de recíproca afinidade, por se situarem na ampla discussão do grau de poder do órgão julgador, elas não deixam confundir-se: o primeiro é decorrência inevitável da natureza abstrata da norma jurídica, que define sua generalidade na função mínima de aplicabilidade e legitimação do direito. $\mathrm{O}$ segundo é decorrência apenas possível de um juízo de valor inferido por meio de premissas que postulam o que consideram como efetivação do projeto constitucional.

E, também, não é em nada inevitável confundir a impossibilidade de resolução de todos os conflitos pela jurisdição estatal e a atividade interpretativa com o que se convenciona chamar lacunas do direito. Mas é oportuno recorrer à observação de que, então ciente da advertência de situações de aparente ausência de normas gerais a versar sobre o caso concreto, o legislador tende a instituir diferentes provisões para tanto.

Exemplificativamente, o artigo quarto do Decreto-Lei n. 4.657/42 passa a letra: quando a lei for omissa, o juiz decidirá o caso de acordo com a analogia, os costumes e os princípios gerais de direito. Complemente-se com a informação de que o recurso a esses instrumentos para o julgamento ocupa espaço residual quando se trata do desempenho da jurisdição estatal, ao passo que, como pode-se extrair da Lei n. 9.307/96, não há ordem para implemento do tipo de conteúdo material referente ao caso sob apreciação na arbitragem.

Sabendo disso, vide, junto a Kelsen (2009), que a aceitação da opinião da existência de lacunas, não raro, está acompanhada de uma pro- 
posta de solução de conflitos pautada na negação do prisma referente ao alcance da ordem jurídica expresso no binômio permissão-proibição. De modo que a consideração do direito como omisso num ou noutro ponto remete antes a uma preferência de política jurídica, a qual se traduzirá numa escolha a ser realizada pela autoridade competente do julgamento do caso concreto.

Se, neste momento, a investigação kelseniana guiou-nos para a rejeição de uma lacuna jurídica propriamente dita, o entendimento estende-se mais além quando, na obra Teoria geral do direito e do Estado, estão pormenorizadas ainda mais as linhas que já haviam sido traçadas acerca da unidade entre o ordenamento jurídico e o Estado em Teoria pura do direito:

O Estado como comunidade jurídica não é algo separado de sua ordem jurídica, não mais do que a corporação é distinta de sua ordem constitutiva. Uma quantidade de indivíduos forma uma comunidade apenas porque uma ordem normativa regulamenta sua conduta recíproca. A comunidade - como assinalado em capítulo anterior - consiste tão somente numa ordem normativa que regulamenta a conduta recíproca dos indivíduos. O termo "comunidade" designa o fato de que a conduta recíproca de certos indivíduos é regulamentada por uma ordem normativa. A afirmação de que os indivíduos são membros de uma comunidade é uma expressão metafórica, uma descrição figurada de relações específicas entre os indivíduos, relações constituídas por uma ordem normativa. (KELSEN, 2016, p. 263)

Se, portanto, Estado e direito constituem aspectos distintos de uma mesma realidade e as teorias dualistas encaminham-se no sentido de conferir-lhes caráter essencialmente diverso com fulcro em preceitos ideológicos a fim de produzir uma mútua fundamentação e obter maior obediência e adesão; e se a aplicabilidade da ordem jurídica mantém-se plena a despeito da inexistência de normas que atribuam determinado dever aos indivíduos; logo é possível assumir que também o exercício do Poder pelo Estado não é lacunar e é manifesto mesmo em caso de omissão. 
Quando é levantada a hipótese de que o Poder faz-se sentir até em casos de omissão, seria razoável a ponderação de que isso só poderia ser verdadeiro se assume-se que toda omissão é conhecida e oportunizada, recorrendo aos estudos levados a cabo por Hart (2009) e Raz (2012) atinentes à omissão no contexto da soberania e da ordem jurídica. A isso junta-se a resposta de que o âmbito desse exercício existe, ainda que restritamente, tão logo são considerados não apenas as variadas fontes através das quais se pode tomar ciência do estado alegadamente faltoso, mas, inclusive, os meios oficiais para tanto, como é o caso do mandado de injunção, previsto no inciso LXXI, artigo $5^{\circ}$ da Carta Nacional e regulado pela Lei n. 13.300/16.

Esse quadro retém sensível atenção quando aponta para um fenômeno a tomar corpo na sociedade brasileira: o ativismo judicial. Para fins de definição, Barroso (2011, p. 6) o expõe como “[...] participação mais ampla e intensa do Judiciário na concretização dos valores e fins constitucionais, com maior interferência no espaço de atuação dos outros dois Poderes". O assunto é, pois, um tópico inserido na discussão do alcance da jurisdição na medida em que reverbera numa outra visão sobre a efetividade da ordem e no modo como aquilo que dispõe deve ser interpretado e, ao mesmo tempo, implica numa ligação com a temática do acesso à justiça a vista de que autores a exemplo de Amaral e Malacrida (2014) subordinam tal acesso à plena fruição dos direitos.

De outra maneira, Lazari (2012) acentua a necessidade de estabelecimento de critérios mais austeros quanto à atuação do magistrado na realização dos direitos sociais sob a ressalva de tal intervenção poder distorcer o acesso à justiça em uma excessiva demanda ao Judiciário.

Sem embargo, a crítica anterior apenas expõe a camada mais imediata e superficial daquela intervenção judicial em relação ao acesso à justiça e ao dano colateral desencadeado sobre os meios privados de solução de conflitos. Isso porque não são realçadas as premissas nas quais o problema se ancora e suas consequências.

$\mathrm{O}$ que primeiramente cumpre ter claro em mente, apesar da franca evidência de que deveria gozar, é que a norma jurídica, por mais que imprima fervor no espírito dos povos que a ela se submetem, não dispõe 
do vigor suficiente para demover as leis naturais de sua regência. Nesses termos, por mais que o parágrafo primeiro do artigo $5^{\circ}$ da Constituição brasileira de 1988 disponha da aplicação imediata dos direitos e garantias fundamentais, a eficácia destes permanece subordinada à lei da escassez.

Ainda que haja o intento de ponderar a constatação acima com a gradual realização das declarações constitucionais, não escapa fator mais nocivo aos ideais democráticos e de ingresso numa ordem jurídica justa e acessível traduzido na dupla premissa sob a qual se apresenta a imiscuição das funções estatais. O primeiro aspecto é a asserção de que o Poder encontra lacunas em seu exercício, o que já começou a ser trabalhado nas linhas acima. $\mathrm{O}$ outro aspecto pretende informar que normas programáticas são cláusulas que estatuem deveres, donde é possível entender a linguagem que, ao tratar do tema, fala especificamente em cumprimento da Constituição.

Não bastasse a fórmula linguística em que se expressam as normas programáticas, pelo que já salta a sua distinção das normas que estabelecem deveres, estas últimas particularizam-se, segundo Raz (2012), por erigir um curso específico de ação. E o contraste que a natureza de um dever proporciona quando se está frente a uma norma programática é que o conteúdo desta se materializa sob inúmeros arranjos, o que se deixa verificar pela multitude de políticas e variáveis empregadas de maneiras e em nações diversas para a consecução de um mesmo fim, e isso sob o primado de respeito à dignidade humana. E essa variedade verte-se no pluralismo político, fundamento da República Federativa do Brasil (BRASIL, 1988, art. $\left.1^{\mathrm{o}}, \mathrm{V}\right)$.

Quando o Judiciário toma posição positiva com aparo naquela dúplice proposição, sua atitude assume erroneamente que determinado curso de ação é evidente e o melhor ou o único possível, pondo-se, portanto, frontalmente contra o pluralismo político e sustentando-se sobre ideologia estatista.

A consequência dessas práticas, em perspectiva mais ampla, descortina-se para o jurisdicionado no instante em que este, encontrando no Judiciário um provedor de suas demandas, desde as mais domésticas, é convidado insistentemente a inclinar-se à "infantilização" e à ignorância 
graduais acerca do exercício da política dentro da sociedade e os efeitos de seus atos como cidadão.

Nesse sentido, ao mesmo tempo em que o Judiciário atrita com outros Poderes, ele estimula a judicialização dos conflitos e adormece os impactos entre o povo e as outras repartições do Poder Político, o que é requisito para a percepção mais apurada da representação política. O processo de desenvolvimento político do cidadão é parcialmente substituído pela atitude paternalista e unilateral que adquire marcas mais desfavoráveis que se no âmbito do Executivo ou do Legislativo, em evidência do reduzido contrapeso participativo na forma de investidura, performance e manutenção do complexo judicial estatal.

No cenário sociopolítico e institucional descrito, os meios privados de resolução de conflitos contribuem em diversas frentes para a solução de algumas dessas dificuldades.

O primeiro nível de contribuição diz respeito ao relaxamento numérico no que toca a quantidade de processos e à absorção dos conflitos e seus impactos na sociedade. É que, exatamente pela natureza privada que ostentam, a sua aplicação restringe-se a uma área de impacto essencialmente menor que aquela percebida pela jurisdição estatal (e nisso está uma das principais características que lhes dão contornos opostos às vias públicas), ainda que contemplada a limitação da decisão judicial entre as partes, visto que, mesmo assim, a produção jurisprudencial e a maior ou menor influência dos precedentes são características de tal sistema. De resto, a característica da especialidade - no sentido estrito, típico da arbitragem, como já relatado alhures - conjuga-se com o insistente e gradual fenômeno das relações jurídicas impregnadas de especificidades técnicas e que ocorre lado a lado à massificação das contendas, o que se verifica sobretudo em virtude do modo de produção e do incremento dos recursos tecnológicos.

A propósito, a emergência de traços tecnocratas faz-se sentir de forma progressiva no ordenamento jurídico, como dá ciência a advertência do professor Jean-Louis Bergel, inspirando-se no magistério de Georges Ripert: 
No mundo contemporâneo, o legislador se preocupa ciosamente com problemas econômicos, sociais, técnicos. Legislando sobre tudo, a regulamentação fica tão precisa que quase já não pode ser feita e compreendida senão por especialistas, e o legislador não pode dispensar o auxílio dos técnicos. Estes já nem sequer se contentam em ser "os auxiliares" dos "juristas"; "pretendem ser seus substitutos". (BERGEL, 2006, p. 86)

Asserido isso, os meios privados de solução de conflitos evidenciam adequada força de captação ao oferecer técnicas idôneas a atender particularidades que moldam as relações socioeconômicas da contemporaneidade.

Etapa mais complexa e intensa de seu desempenho na harmonização da dinâmica social está na imersão dos interessados na solução de seus conflitos. Mesmo nos métodos heterocompositivos, os sujeitos acessam a faculdade de eleger diretamente não apenas os julgadores, mas os parâmetros materiais e procedimentais que deverão ser observados do começo ao fim da experiência arbitral.

Isso quer igualmente apontar que aquele maior envolvimento dos indivíduos projeta-se no amadurecimento destes, sendo isso visível no próprio treinamento dispensado aos profissionais mediadores e conciliadores, os quais são orientados no sentido de compreender e desempenhar suas funções como oportunidade de crescimento e aperfeiçoamento da partes, a exemplo do que instrui o Manual de mediação judicial do Conselho Nacional de Justiça.

Se, no nível micro, a promoção e o emprego das vias privadas emancipam amplamente os interessados no gerenciamento de suas relações e, no nível macro, tais meios fomentam a fragilização da dependência tecnicista da legislação, o contrapeso à inflação da atividade criativa dos tribunais e, por conseguinte, o abrandamento das colisões entre as repartições do Poder do Estado, constituem uma ponte indireta às esferas superiores da vida política.

De maneira que os meios privados não se resumem a vias diretas de pacificação, mas insistem em seu objetivo indireto de participação 
política na medida em que desobstrui os canais de comunicação entre o povo e as suas representações e corrige algumas distorções no exercício do Poder. Assim, a questão de sua efetividade serve como um parâmetro de avaliação da atividade política e do fortalecimento das instituições.

\section{O Acesso à Justiça e o Prenúncio a uma Nova Perspectiva}

$\mathrm{O}$ acesso à justiça, ainda quando entendido minimamente como direito de ação, não é um dado uniformemente demonstrável pela análise jurídica e lógica, consoante a lição de Kelsen (2009) no tocante aos direitos subjetivos. As formas pelas quais a faculdade de mover a estrutura judicial é distribuída se alteram conforme o sistema jurídico, o recorte temporal e entre as distintas searas em que, organizacional e didaticamente, se ramifica a produção legislativa.

A título de ilustração, se aponta frequentemente para a notória diferença entre o modo de realização do direito de ação no ramo civil, cunhado pela ampla autonomia privada, e na esfera criminal, onde o mesmo direito submete-se, em vários casos, por alegadas razões de ordem pública, a autoridades oficialmente designadas para tanto. Todavia, não há nada que possa fornecer uma razão irretocável para que assim seja e não o inverso ou qualquer outra variação.

Portanto, a investigação pautada na perspectiva normativista não nos oferece dado conclusivo para precisar mais ainda a natureza e o conteúdo do acesso à justiça. A complicação decorrente disto é que a metodologia terá de orientar-se pela leitura contingencial a partir dos fatores relevantes e agregados à pesquisa: a legislação em vigor; a prática e a política jurídicas e judiciárias; e a interpretação doutrinária.

No ordenamento jurídico brasileiro, reside no inciso XXXV do artigo $5^{\circ}$ da Constituição Federal de 1988 o suporte legal da garantia, com o seguinte texto: a lei não excluirá da apreciação do Poder Judiciário lesão ou ameaça a direito. 
Uma interpretação estrita do dispositivo provocaria a opinião pela equivalência entre a inafastabilidade e a obrigatoriedade da prestação jurisdicional.

Apesar dessa possibilidade interpretativa, os atuais quadros doutrinários e político-jurídicos dispõem de abundante material a indicar univocamente novo direcionamento das autoridades e dos pesquisadores quanto ao problema.

A esse respeito, constitui um dos primeiros marcos o estudo de Cappelletti e Garth (1988) sobre as três ondas de acesso à justiça, no que se capta atenção especificamente para a última destas. Trata-se da fase em que o conceito trabalhado neste momento encontra maior amplitude e principia a envolver vias outras que não a estatal.

Abre também espaço para o intento desta perquirição a declaração do Supremo Tribunal Federal, em sede de recurso nos autos (SE 5.206) a discutir homologação de sentença estrangeira, pela constitucionalidade da Lei n. 9.307/96 - documento legal que regula a arbitragem - rejeitando de vez as opiniões pela obrigatoriedade da prestação jurisdicional e sedimentando a compatibilidade daquela via privada com as regras e os princípios constitucionais. E, mais recentemente, é de distinguir-se, sem hesitação, a Resolução n. 125 do Conselho Nacional de Justiça, cujo principal desiderato é a promoção e renovação da política pública de tratamento adequado de conflitos, pelo que confere sensível ênfase, entre outros, à prática, ao ensino e à divulgação da mediação e da conciliação. Na mesma linha estão as inovações trazidas pelo novel Código Processual Civil (Lei n. 13.105/15), por meio de seu terceiro artigo, com o indubitável suporte à resolução consensual dos conflitos e a determinação de o Estado conformar-se tanto quanto possível a essas formas; pelas alterações (Lei n. $13.129 / 15$ ) postas ao documento legal que regula a arbitragem, ampliando o conceito de arbitrabilidade e, por conseguinte, a aplicação do instituto; e pela edição e promulgação da Lei n. 13.140/15 a disciplinar a mediação.

A isso segue o seguinte entendimento concernente ao destinatário do inciso XXXV do artigo quinto da Lei Básica: de acordo com Mancuso (2014), a cláusula expressa naquele dispositivo dirige-se diretamente ao legislador, impondo-lhe o dever de abster-se de pôr comandos na quali- 
dade de impedimentos ao jurisdicionado de demandar seus interesses no Judiciário.

Vê-se, chegada essa etapa, o embaraço que é, num sistema jurídico-político que se pretende não-autoritário, identificar na regra em comento um dever de sempre atrair o aparato estatal ou, inclusive, um mero direito de peticionar. É que a oferta da cláusula, nesses termos, tropeça em duas barreiras que se cruzam e se agravam mutualmente, a saber, a limitação de recursos e a renovação e a multiplicação perenes das necessidades e dos interesses ajuizáveis humanos ou, em outras palavras, das pretensões juridicamente inteligíveis.

É possível, entretanto, tentar emendar a observação acerca da limitação de recursos nas seguintes considerações: Os meios privados de resolução de conflitos encontram-se sujeitos a custos e, por isso mesmo, submetem-se à mesma crítica. Não é, certamente, objeto de discordância a primeira parte da afirmação, mas a segunda é precipitada, uma vez que desconhece a diferença entre as fontes e as formas de custeio das atividades públicas e particulares, o que se cuida esclarecer agora, em grande parte, com espeque em estudo do professor Sabbag (2016). Em primeiro lugar, sem ignorar a importância (ainda que mediata) da função judicial que permeia toda sociedade, o aumento do número da estrutura judicial age na extensão em que se faz sentir o poder de tributação do Estado, o qual onera tanto aqueles que utilizam mais frequentemente como aqueles que, nunca ou quase nunca, dispõem do serviço. Os expressivos salários dos magistrados e servidores, os gastos em infraestrutura e os serviços terceirizados, para fazer visualizar apenas alguns, amontam custos que recaem indiscriminadamente sobre os tributados e representam larga porção do orçamento público. Por outro lado, os meios privados retêm vinculação mais estreita entre as despesas efetuadas e os beneficiários diretos do serviço, o qual pode ser até bem menos dispendioso que o da máquina estatal ou beirar a genuína gratuidade, como é o caso das modalidades autocompositivas sem presença de terceiros.

Ademais, outra questão de ordem econômica toca a sensibilidade do profissional frente à demanda que lhe procura. Isto é, embora reconhecido o enfraquecimento causado pela seleção de profissionais da área em 
comento na condição de servidor público, conciliadores, mediadores ou árbitros podem ter sua remuneração, atuação e permanência no respectivo cargo reconsideradas a depender do feedback proporcionado pelos seus clientes. Essa sensibilidade atinge em escala reduzidíssima os servidores do Judiciário, em especial o magistrado, em vista das garantias de que se revestem e dos princípios que garantem que as atividades por eles desempenhadas repousem nos parâmetros do Estado Democrático de Direito, donde se pode dar realce ao princípio do juiz natural (incisos XXXVII e LIII do artigo $5^{\circ}$ da Constituição Brasileira de 1988).

Resta inviabilizada a solução através do crescimento quantitativo do aparato encarregado da resposta jurisdicional, dado que seguirá, de pronto, atrasada e gravosa. E, mais que isso, a proposta desenrola-se num problema cíclico quando constatado que o aumento da oferta repercute na realimentação da demanda, concorde na lição de Mancuso (2014).

A readequação da proposta é posta na seguinte questão: se, com base no inciso XXXV, artigo $5^{\circ}$ da Constituição de 1988, não é possível nem desejável a substituição total do Poder Judiciário e se a solução de incremento quantitativo não alcança êxito, resta redimensionar o núcleo de acesso à justiça.

Percebendo isso, Mancuso (2014) refaz o problema com esteio na realocação da jurisdição estatal na ordem das instâncias adequadas para se dirimir um conflito.

[...] a função judicial precisa ser urgentemente repensada e reciclada, colocando-se em pauta uma reavaliação dessa função estatal, que então deixaria de operar como uma oferta primária (como o induz uma leitura literal e apressada do art. 5. ${ }^{\circ} \mathrm{XXXV}$, dita garantia de acesso à Justiça), para ser vista como uma cláusula de reserva, a saber: uma oferta residual, para os casos que, ou não se afeiçoam à resolução pelos meios auto e heterocompositivos, em razão de singularidades da matéria ou das pessoas concernentes, ou, pela complexidade da crise jurídica, reclamam cognição judicial ampla e exauriente. (MANCUSO, 2014, p. 45)

O que é exposto nessas linhas produz uma consequência mais ampla talvez que a pretendida. A fim de elucidar o novo passo que avança 
nesta pesquisa, é de rememorar junto com Bonavides (2004) que as cláusulas pétreas gozam da qualidade de limites materiais ao poder de reformar e, com Aranha (2000), que tais dispositivos constitucionais detêm um núcleo a conter sua configuração essencial.

Para que algo seja alocado em posição residual é rigorosamente lógico que o seja em vistas a outro objeto, em razão do qual será classificado como remanente, perfazendo uma relação necessária de complementariedade. Por exemplo, quando se habitua a dizer, por considerações materiais, que o Direito Penal funciona como ultima ratio do ordenamento jurídico, passa a ser de imperiosidade formal que, dentro do seu grupo, se repute a existência de algo mais que não de si mesmo apenas. E, ainda que se cogite objetos híbridos, aquela relação só será existente na proporção em que se dirige às partes que destoam da natureza do elemento que pretende ser residual (se A é residual em relação a B e, por algum motivo, se julga preferível destacar a natureza do primeiro por meio de uma combinação $\mathrm{AB}$ em vez de apenas $\mathrm{B}$, tal essência é reforçada apenas em relação ao segundo componente da combinação).

Tem-se tratado isso na divisão dos tipos de meios de resolução de conflitos, quanto à sua natureza, como apenas dois: privados ou estatais. Mas, a esse respeito, se adverte que o autor atribui caráter residual tão somente à função judicial, de modo que antecipadamente irrompe a crítica de que a inclusão das vias privadas como contraparte que dá o exato sentido da residualidade não é conclusiva, haja vista a presença de outros mecanismos para desempenhar a mesma contribuição. Mas é importante lembrar que esses alegados outros métodos recaem na mesma crítica destacada na análise material que dá suporte à concepção da cláusula de reserva. Seja porque atraem os inconvenientes da limitação de recursos e da tributação, seja porque resultam na utilização de meios privados nas instalações estatais, o que não lhes distorce a natureza, ou, finalmente, porque têm uma área de aplicação relativamente muito restrita, como é o caso dos conflitos dirimidos em sede administrativa.

Remodela-se, assim, a noção aqui cotejada do professor Mancuso a fim de nela enquadrar os meios estatais de resolução de conflitos, colhendo por corolário a inclusão da sua contraparte privada. Ou seja, uma inter- 
pretação mais contida quanto ao uso das primeiras, por relevantes considerações materiais discernidas acima, reflete-se diretamente na ampliação movida pela necessidade lógica de redefinir a extensão e o conteúdo do núcleo do direito fundamental de acesso à justiça com sua recepção das vias privada, abrigando-as de quaisquer normas que empreendem a supressão do emprego ou a desnaturação da essência desses meios.

Por último, emerge a crítica de que os meios privados de solução de conflitos não podem banhar-se da condição de cláusula pétrea por possuírem natureza meramente instrumental, pelo que, se fossem limites materiais à atividade legislativa, vulgarizariam aquela instância protetiva, enrijecendo sobremodo a Constituição, dado que a instrumentalidade antes pressupõe disponibilidade e manejo. Para isso se faz remissão às seções anteriores deste trabalho, em que os meios privados de solução de conflitos foram particularizados em sua idoneidade a conjugar-se e imbricar-se intrinsecamente com os postulados da dignidade humana e da harmonia institucional. Além disso, eles não são simples métodos, mas cada um abrange um conjunto de métodos que se organizam e até se cambiam para determinado fim, possuindo natureza de institutos jurídicos. Por essa razão é que se destaca, ao longo dessas linhas, a maior preferência pelos vocábulos "meio" e "via" para transbordar a conotação excessivamente instrumental que a palavra "método" comunica. E cabe mesmo mencionar que determinadas ações judicias, as quais, a princípio, também podem ser contempladas sob o ponto de vista de sua instrumentalidade, encontram resguardo expresso no alto bojo constitucional, como é o caso do habeas corpus (artigo $5^{\circ}$, inciso LXVIII) e do habeas data (artigo $5^{\circ}$, inciso LXXII). A ação judicial, tomada no sentido mais estrito, é um veículo por meio do qual determinado direito material busca ser efetivado. Porém, a idoneidade de certos objetos é tão própria e tão afinada com seu objetivo que acabam por extravasar sua silhueta instrumental e confundir-se, no âmbito protetivo, com sua finalidade à semelhança de um amálgama, tal como acontece com o habeas corpus e o habeas data e, respectivamente, os direitos à liberdade e à informação. Os meios privados sinalizam esse fenômeno com ainda mais força tão logo se percebe que se ligam a uma miríade de direitos espalhados por todas as searas do ordenamento jurídico. 
A existência e a proteção dos meios privados são logicamente necessárias para que o direito de acesso à justiça não se converta no mero acesso ao Judiciário e às complicações que disso decorrem.

\section{Conclusão}

A prestabilidade dos meios privados na administração de conflitos de interesses é o aspecto mais saliente na temática correspondente e de modo diverso não poderia ser, pois é justamente pela compatibilidade de seus métodos com a resolução de contendas que eles encontram sua razão de ser, aquilo que mais lhes caracteriza.

Embora saliente, não é obrigatório que essa qualidade ocupe sempre o maior espaço de discussão, apesar de ser em função dela que o restante das análises orbita. $\mathrm{O}$ que pode suceder é que outras características que compõem a descrição do objeto e as relações nutridas entre este e outros pontos da ordem jurídica ofusquem-se com aquela reiterada abordagem.

Entrementes, esta investigação ofereceu abrir a contextualização que torna visíveis as formas como os meios privados de resolução de conflitos alcançam fenômenos sociais, econômicos, culturais, políticos e, é claro, jurídicos que, longe de estar esgotados nestas breves linhas, dialogaram entre si para moldar um quadro mais amplo do problema.

O risco de uma reenquadramento nessas proporções é desfocar a imagem central em favor da pluralidade dos fatores apresentáveis. Todavia, se é proposto discutir os meios privados em relação à possibilidade de proteção constitucional, é indispensável que se o faça com vistas à garantia de acesso à justiça, a qual requer, inevitavelmente, essa maior abertura por conta da inocuidade de promover os objetivos elencados apenas com apoio em estatísticas e também da impossibilidade de uma fórmula ideal de acesso à justiça.

Ao fazer isso, o trabalho colheu os seguintes resultados: 1) A soberania, não mais confundida com a justiça ou com a origem desta, é compatível com formas privadas de resolução de conflitos, compartilhando com elas, inclusive, um de seus princípios, o qual toca a dignidade da 
pessoa humana na proporção em que se funda em característica inerente ao ser humano. Desse modo, a relação entre as vias privadas e as estatais não é mutualmente excludente, donde a ordem de surgimento de um ou de outro não é tão relevante quanto a cooperação que exercem. Significa ainda dizer que um não se beneficia com o insucesso do outro, sendo-lhes comuns as causas últimas que obstruem seu desenvolvimento. 2) A aplicação de táticas não estatais não afunila seus efeitos exclusivamente às partes que as utilizam, senão têm reflexo institucional, dialogando com pontos da teoria geral do direito, ao amenizar as dificuldades sentidas quando considerados a natureza da norma jurídica, a atividade legislativa e o processo hermenêutico. Ilumina-se o caráter institucional dos meios privados de resolução de conflitos para além de sua instrumentalidade. 3) Apenas após denunciar e afastar as visões incompatíveis de soberania e sustentar aquela ação interinstitucional é possível confrontar livremente a noção de acesso à justiça com ponderações que reinterpretam seu núcleo diante dos limites formais e materiais apresentados na investigação. Não se trata de uma interpretação dentre várias outras possíveis e, por isso, arbitrariamente substituível. O acesso à justiça perde o seu próprio significado e, na melhor das hipóteses, decai para a mera hipótese de direito de ação insuficiente, se não recepciona, em seu bojo constitutivo, os meios privados de resolução de conflitos.

\section{Referências}

AMARAL, Sérgio Tibiriçá. MALACRIDA, Guilherme Bahia. Ativismo judicial: troca de sujeitos e a efetivação de normas programáticas no ordenamento jurídico brasileiro. In: SIQUEIRA, Dirceu Pereira; OLIVEIRA, Flávio Luis de. (org.). Acesso à justiça e concretização de direitos. 1. ed. Boreal: Birigüi, 2014. p. 229-248.

ARANHA, Márcio Iorio. Conteúdo essencial das cláusulas pétreas. Revista Notícia do Direito Brasileiro, [s.l.], v. 7, p. 389-402, 2000. BACELLAR. Roberto Portugal. Mediação e arbitragem. São Paulo: Saraiva, 2012. 
BARROSO, Luís Roberto. Judicialização, Ativismo Judicial e Legitimidade Democrática. In: COUTINHO, Jacinto Nelson de Miranda; FILHO, Roberto Fragale; LOBÃO, Ronaldo. (org.). Constituição \& Ativismo Judicial: limites e possibilidades da norma constitucional e da decisão judicial. Rio de Janeiro: Lumen Juris, 2011. p. 275-290.

BERGEL, Jean-Louis. Teoria geral do direito. 2. ed. São Paulo: Martins Fontes, 2006.

BONAVIDES, Paulo. Curso de Direito Constitucional. 15. ed. São Paulo: Malheiros, 2004.

BRASIL. Conselho Nacional de Justiça. In: AZEVEDO, André Gomma de. (org.). Manual de mediação judicial. 6. ed. CNJ: Brasília, 2016. p. 09-259.

BRASIL. Conselho Nacional de Justiça. Resolução n. 125 de 29/11/2010. Disponível em: http://www.cnj.jus.br/busca-atosadm?documento=2579. Acesso em: 12 nov. 2016.

BRASIL. Constituição da República Federativa do Brasil. Brasília, DF: Senado Federal: Centro Gráfico, 1988.

BRASIL. Decreto-Lei n. 4.657, de 4 de setembro de 1942. Lei de introdução às normas do Direito Brasileiro. Diário Oficial da República do Brasil, Rio de Janeiro, 4 set. 1942. Disponível em: http://www. planalto.gov.br/ccivil_03/decreto-lei/Del4657compilado.htm. Acesso em: 20 jan. 2017.

BRASIL. Lei n. 9.307, de 23 de setembro de 1996. Dispõe sobre a arbitragem. Diário Oficial da República do Brasil, Brasília, DF, 23 set. 1996. Disponível em: http://www.planalto.gov.br/ccivil_03/leis/L9307. htm. Acesso em: 20 jan. 2017.

BRASIL. Lei n. 13.105, de 19 de março de 2015. Código de Processo Civil. Diário Oficial da República do Brasil, Brasília, DF, 19 mar. 2015. Disponível em: http://www.planalto.gov.br/ccivil_03/_ato20152018/2015/lei/113105.htm. Acesso em: 20 jan. 2017. 
BRASIL. Lei n. 13.140, de 26 de junho de 2015. Dispõe sobre a mediação entre particulares como meio de solução de controvérsias e sobre a autocomposição de conflitos no âmbito da administração pública. Diário Oficial da República do Brasil. Brasília, DF, 26 jun. 2015. Disponível em: http://www.planalto.gov.br/ccivil_03/_ato20152018/2015/Lei/L13140.htm. Acesso em: 20 jan. 2017.

BRASIL. Superior Tribunal Federal. Agravo regimental na sentença estrangeira 5.206-7. Disponível em: http://redir.stf.jus.br/paginadorpub/ paginador.jsp?docTP=AC\&docID=345889. Acesso em: 11 jan. 2017.

CAPLAN, Bryan; STRINGHAM, Edward Peter. Privatizing the adjudication of disputes. Theoretical Inquires in Law, [s.l.], v. 9, n. 2, p. 503-528, 2008.

CAPPELLETTI, Mauro; GARTH, Bryant. Acesso à justiça. Tradução de Ellen Gracie Northfleet. Porto Alegre: Sergio Antonio Fabris Editor, 1988.

HART, Herbert Lionel Adolphus. O conceito de Direito. 1. ed. São Paulo: Martins Fontes, 2009.

HOBBES, Thomas. Leviatã: ou matéria, forma e poder de um Estado eclesiástico e civil. 1. ed. São Paulo: Martin Claret, 2014.

HUTCHESON, Francis. Logic, metaphysics, and the natural sociability of mankind. Indianapolis: Liberty Fund, 2006.

HUTCHESON, Francis. Philosophiae moralis institutio compendiaria with a short introduction to moral philosophy. Indianapolis: Liberty Fund, 2007.

KELSEN, Hans. Teoria geral do direito e do Estado. 5. ed. São Paulo: Martins Fontes, 2016.

KELSEN, Hans. Teoria pura do direito. 8. ed. São Paulo: Martins Fontes, 2009.

LAZARI, Rafael José Nadim de. Ativismo judicial e acesso à justiça: uma faca de dois gumes. In: SIQUEIRA, Dirceu Pereira; OLIVEIRA, Flávio Luis de. (org.). Acesso à justiça: uma perspectiva de democratização da administração da justiça nas dimensões social, política e econômica. 1. ed. Boreal: Birigüi, 2012. p. 355-372. 
LOCKE, John. Dois tratados sobre o governo. 1. ed. São Paulo: Martins Fontes, 1998.

MANCUSO, Rodolfo de Camargo. A resolução dos conflitos e a função judicial no contemporâneo Estado de Direito. 2. ed. São Paulo: Revista dos Tribunais, 2014.

PAVLOVIC, Dusan. Rousseau's theory of sovereignty. 1997. $100 \mathrm{f}$. Dissertação (Mestrado) - Department of Political Science, Central European University, Budapeste, 1997.

PLATÃO. A República: ou sobre a justiça, diálogo político. 2. ed. São Paulo: Martins Fontes, 2014.

RAZ, Joseph. O conceito de sistema jurídico: uma introdução à teoria dos sistemas jurídicos. 1. ed. São Paulo: Martins Fontes, 2012.

REALE, Miguel. Filosofia do direito. 19. ed. São Paulo: Saraiva, 1999.

ROUSSEAU, Jean-Jacques. O contrato social: princípios do direito político. 3. ed. São Paulo: Martins Fontes, 1996.

SABBAG, Eduardo. Manual de Direito Tributário. 8. ed. São Paulo: Saraiva, 2016.

SCAVONE JÚNIOR, Luiz Antonio. Manual de arbitragem, mediação e conciliação. 5. ed. Rio de Janeiro: Editora Forense, 2014.

SPENGLER, F. M. Mediação: um retrospecto histórico, conceitual e teórico. In: SPENGLER, Fabiana Marion; SPENGLER NETO, Theobaldo. (org.). Mediação enquanto política pública: a teoria, a prática e o projeto de lei. 1. ed. Santa Cruz do Sul: EDUNISC, 2010. p. 17-57.

STEELE, Dean Allen. A comparison of Hobbes and Locke on natural law and social contract. 1993. 63f. Dissertação (Mestrado) - Faculty of the Graduate School, University of Texas, Austin, 1993.

VOEGELIN, Eric. A natureza do direito e outros textos jurídicos. Lisboa: Vega, 1998. 
Clarindo Epaminondas de Sá Neto é doutor em Direito, Política e Sociedade (UFSC). Mestre em Direito Constitucional (UFRN). Professor da graduação, do mestrado e do doutorado em Direito (UFSC).

E-mail: clarindoneto@gmail.com

Endereço profissional: Campus Universitário Reitor João David Ferreira Lima, s/n, Trindade, Florianópolis, SC. CEP: 88040-900.

ORCID: https://orcid.org/0000-0001-7687-6322

George Lucas Souza Diógenes é mestrando em Direito, Democracia e Conflitos Socioeconômicos pela Universidade Federal Rural do Semiárido.

E-mail: lucasdiogenes.sgu@gmail.com

Endereço profissional: Avenida Oito de Novembro, n. 976, Centro, Jaguaribe, CE. CEP: 63475-000.

ORCID: https://orcid.org/0000-0002-9830-0540

José Albenes Bezerra Júnior é doutor em Direito pela Universidade de Brasília. Mestre em Direito pela Universidade Federal do Rio Grande do Norte. Graduado em Direito pela Universidade de Fortaleza. Professor da Universidade Federal Rural do Semiárido. Coordenador do Grupo de Estudos em Conflitos e Acesso à Justiça.

E-mail: albenes.junior@ufersa.edu.br

Endereço profissional: Rua Francisco Mota, n. 572, Presidente Costa e Silva, Sala 17 do CCSAH, UFERSA. Mossoró, RN. CEP: 59625-900.

ORCID: https://orcid.org/0000-0002-7598-8856 